\title{
Learning Outcomes of Mobile and Tablet Application Courses for Taiwanese Older Adults
}

\author{
Jen-Yi, Chao ${ }^{1, \mathrm{a}}$, Hsiao-Chi Kao ${ }^{2, \mathrm{~b}}$, Yi-Hsin, $\mathrm{Yeh}^{3, \mathrm{c}}$ \\ ${ }^{1,2,3}$ Graduate School of Curriculum and Instructional Communications and Technology, National Taipei University of Education \\ 4, Sec. 2, Heping E. Rd., Da-an District, Taipei City 106, Taiwan (R.O.C.) \\ Tel: +886 227321104 Ext. 55532、+886 918 2-53896 Fax: +886 2739-4270 \\ E-mail:jychao@tea.ntue.edu.tw'bcheer518@gmail.com,cs9003223@stu.ntue.edu.tw
}

\begin{abstract}
This study examined older adults learning experiences and outcomes of a smart device course. The analysis, design, development, implementation, and evaluation model and cognitive apprenticeship strategy were used for course development. The course comprised eight-week classes, with one class per week and 2 hours per class. Purposive sampling was used to select 40 participants, with an average age of 72 years. The 5-point Likert scale and dependent sample t-test were used to determine the participants' information technology (IT) literacy. The pretest and posttest mean values of IT literacy were 3.03 and 4.19. A significance level of $p=.001$ was obtained, which revealed that the course significantly increased the IT literacy of the participants. The results indicated that the participants were satisfied with the course content, teaching, teaching assistants, and facilities, with an average score of $>4.5$. Moreover, the participants indicated a willingness to engage in continuous learning.
\end{abstract}

Key words:elderly learning, information literacy, learning outcomes, older adults, smart device course

\section{Introduction}

According to a survey of Taiwan's older adults released by the Institute for Information Industry [1], 48.2\% of older adults in Taiwan over the age of 65 own smartphones. Although calling relatives and friends was listed as the primary reason for owning a smartphone, $90 \%$ of respondents also reported using the instant messaging application LINE. Among 55- to 64-year-olds, smartphones were used more for LINE than for making calls. These figures indicate the extent to which Taiwan's middle-aged and older adults have incorporated new technologies into their daily lives. Many desire to learn information technology (IT) in order to interact with their friends and relatives, keep up with modern society, and improve their quality of life [2]. According to a survey conducted by Taiwan Network Information Center (TWNIC), older adults over the age of 60 who access the Internet mostly use mobile phones to do so, and more than half have experience using instant messaging software. The proportion of people above the age of 65 using LINE is even higher than among other age groups. Among those who do not access the Internet, reasons include being unfamiliar with or fearful of computers, being out of interests, and worrying about being too old for the technology [3-4]. With these concerns in mind, we designed and developed a course suitable for older adults to increase familiarity with smart devices among older adults while helping them adapt to the changes in modern life brought about by the rise in IT.
The purpose of this study was to develop a suitable course on how to use smart devices designed for older adults in Taiwan. The developed course would be used to explore whether such courses could help improve IT literacy and willingness to engage in future learning.

Older adults from an international retiree organization in Taipei, Life Ascending International (LAI), were recruited as participants to explore the following questions:

1. Will participation in a course on how to use smart devices enhance IT literacy of older adults?

2. Will participation in a course on how to use smart devices improve participants' willingness to engage in future learning about IT and smart devices?

\section{Literature \\ A. Learning Requirements of Older Adults}

According to the margin theory of needs proposed by McClusky, the learning needs of older adults include coping needs, expressive needs, contributive needs, influence needs, and transcendence needs [5]. Older adults learn the knowledge and skills required in old age, along with the physical, mental, and social needs by learning interest-related classes or volunteering. Those who are willing to express their opinions may choose to join a club and continue to participate in social events. Older adults, facing changes in their living conditions and behavior patterns caused by technology, perceive that they must adapt to new interactive modes of interpersonal relationships. Thus, they must learn how to effectively use IT such as smart devices and the Internet to participate fully in daily life. With more free time after retirement, older adults are able to focus on specific goals and interests. Older adults often have various reasons for desiring to continue learning [6].

In Taiwan, older adult education is held at a variety of venues, including the National Open University, the Senior Citizen Center, community colleges, Active Aging Learning Resource Centers, older adults learning camps, and senior citizen learning institutions run by civil society and religious organizations [7]. In addition, older adult learning camps often cooperate with universities and colleges to provide convenient and diverse lifelong learning opportunities for older adults. Wei applied McClusky's theory to analyze the curriculums in Taiwan's Active Aging Learning Resource Centers and found that the largest number of courses were interest courses $(56 \%$ of the total course hours), followed by basic courses (31\%) [8]. Fewer courses were based off of contributing and influence and surpassing curriculums. However, basic courses (e.g., IT courses) that meet coping needs, and self-transcending courses (e.g., spiritual courses) are those most required by older adults; these courses help them face a rapidly changing society and affirm the meaning and value of life. 


\section{B. Information Literacy Among Older Adults}

Information literacy includes "traditional literacy," "media literacy," "computer literacy," and "network literacy" [9]. McClure noted that possessing network literacy allows individuals to work and live more efficiently and considered it a key competency for citizens of the future. The ability of information literate individuals to search for information to solve problems can increase self-confidence, enhance learning and research skills, and increase motivation for further learning.

Since 2008, numerous learning institutions for older adults and courses pertaining to information technology have been established in Taiwan. Research has indicated that older adults who have learned to use tablet computers or online communities display increased satisfaction in their access to information, social interactions, daily living, and emotions and are thereby encouraged to continue learning[10]. Using the four aspects of traditional, media, computer, and network literacy, Chen explored the information literacy of older adults living in Tainan's Yong Kang District and reported that their familiarity and cognition regarding computer and network literacy were lacking[11]. Thus, although new technology products and services such as computers, tablets, mobile phones, and the Internet can aid work, living, and study, many older adults remain unfamiliar with such products. This study further investigated the basic information technology competencies of older adults.

Considering that the teaching objective in this study was to help older adults learn how to use smart devices in their daily lives, we adopted performance assessment as the primary method for evaluating learning outcomes. We also conducted IT literacy self-evaluations before and after the course. The "Senior IT Literacy Scale" developed by Chao focuses on the basic IT skills and knowledge required to solve daily problems among older adults and was developed from the four capacity-oriented aspects of "information needs and access," "information evaluation," "information use and problem solving," and "IT and human society"[12]. The scale content was based on the older adults' smart device use and commonly raised topics in an Internet community. A survey on IT literacy was employed to not only determine the current IT literacy of older adults in Taiwan but also whether the participation of older adults in a smart device course enhanced their IT literacy and willingness to learn.

\section{Development of the Smart Device Course}

This study adopted the ADDIE ("analysis, design, development, implementation, and evaluation") [13] model and cognitive apprenticeship strategy for curriculum development and design and as a teaching strategy, respectively.

When older adults encounter new situations and objects, they may feel concerned about their physical deterioration and the psychological obstacles. Fear and anxiety with unfamiliar IT may affect their willingness to learn and apply information [14]. Wei et al. argued that instructors should learn more about the characteristics of older adults such as their physical and psychological states, social roles, and life histories to enhance teaching efficiency and guide and encourage older adults to engage in autonomous and continuous learning [15]. To develop an appropriate curriculum, we must first understand the learning needs and physical and mental characteristics of Taiwan's older adults. This study employed the ADDIE model for the course design, which features the learner at its center. Among teaching models, the ADDIE model is the easiest to implement and the most commonly used, which helps course developers design courses because they can follow existing systematic planning procedures to ensure instructional design quality

Cognitive apprenticeship emphasizes learning in real-life situations and encourages learners to gain deeper understandings of the taught content [16]. Cognitive apprenticeship teaching should begin from the most basic concepts. Jiang proposed several approaches for reducing the digital divide between generations, including having younger generations serve as "digital classmates" for older adults, linking with communities to provide a learning space for digital technology courses suitable for older adults, and using user-friendly and easy-to-use portable devices such as smartphones and tablet computers for learning [17].

The distinguishing characteristic of the present study was integrating all the three aforementioned approaches by Jiang to offer mobile-device learning courses in communities with a learning assistant team formed from graduate students. While implementing cognitive apprenticeship, older adults were provided with guidance and assistance to reduce their concerns regarding new technology or other learning difficulties caused by physical and psychological factors. This also helped instructors to quickly move through lesson materials while creating a friendly learning environment that encouraged older adults to participate in digital technology learning.

\section{Research method}

\section{A. Design}

A questionnaire was issued to determine the participants' learning requirements, motivation, and attitude toward learning IT. The ADDIE model was used to develop a course suitable for older adults wishing to learn how to use smart devices. Based on the physical and mental characteristics of Taiwan's older adults, the cognitive apprenticeship teaching strategy was chosen for delivering the course content. We collected qualitative and quantitative data to understand the learning outcomes, including the participants' class work, interactive feedback from the class LINE group, IT literacy, and satisfaction surveys. A 5-point Likert scale was used to determine IT literacy and course satisfaction. Dependent sample t-test was used for data analysis.

\section{B. Research subject}

This was a case study using purposive sampling. The participants were retired older adults who were mainly members of Life Ascending International, an international organization with members across four continents, including approximately 400 members in Taiwan. In total, 40 participants enrolled in the designed course; from these participants, we obtained 39 and 36 valid pretest and posttest responses, respectively. The majority were women, with a male: female ratio of approximately 1:5. Half of the participants were aged 65-74 years and the average age was 72 years. Most were well educated-half of all participants were educated to a bachelor's degree level or higher.

\section{C.Research tools}

This study employed interviews, questionnaires, and focus groups for qualitative and quantitative data collection.

(A)Qualitative tools: In the preparation stage of the course, interviews were conducted to gain a preliminary understanding of the background of the participants, ideas for the course, possible venues, and related support. During teaching, 
classroom observation was performed, and each class was recorded to allow the group members' learning experience to be reviewed, including any problems encountered and participants' attendance and learning attitudes. Interactions between the teachers and students were taken as references to adjust the teaching process. In addition, messages shared in the class' LINE group served as further data for assessing the learning outcomes. At both the beginning and the end of the course, open-ended questionnaires were used to determine the participants' learning motivation and to receive feedback on the curriculum.

(B)Learning Attitude Scale: Before the start of the class, a structured questionnaire was used to collect and analyze the participants' demographic information, learning attitudes, learning needs, and other quantitative data; this data served as a reference for the curriculum design and teaching. Before and after the course, we evaluated IT literacy using a self-developed IT literacy questionnaire for older adults. A satisfaction questionnaire with a 5-point Likert scale was also administered to collect participants' opinions on the content and teaching of the course, including whether the content of the course met their requirements, whether they were satisfied with the lecturer's teaching methods and knowledge, and how they felt about the teaching venue and related services. The IT literacy questionnaire for older adults comprised 12 evaluation indicators from four dimensions: information needs and access; information evaluation; information use and problem-solving; and IT and human society. According to reliability analysis of the overall scale, the Cronbach's alpha were respectively 0.95 and 0.92 for the pretest and posttest, indicating that the scale possessed excellent reliability.

\section{Research result}

The course was taught through eight classes over 8 weeks, and it significantly increased the IT literacy of the participants. The participants found the course satisfying and felt it fulfilled their requirements. They were willing to continue learning through this course.

\section{(A)Course satisfaction}

The course satisfaction results indicate that the curriculum sati sfied the participants' requirements. They were satisfied with th e course content, teaching, assistants, and learning environment, and the average satisfaction score was $>4.5$ (Table 1).

Table1.Course Satisfaction Results

\begin{tabular}{lll}
\hline & Mean & SD \\
\hline 1. Did the course meet your learning requirements? & 4.58 & .500 \\
\hline 2. Satisfaction with the units & 4.67 & .478 \\
\hline 3. Satisfaction with the teaching & 4.69 & .525 \\
\hline 4. Satisfaction with the assistants & & .454 \\
\hline 5. Satisfaction with the learning environment & 4.61 & .549 \\
\hline 6. Satisfaction with the overall service & 4.67 & .535 \\
\hline
\end{tabular}

Based on interview data, the students were satisfied with the curriculum and instructor teaching on the mobile device course and provided the following opinion:

The teacher's instruction was lively and active and stimulated our potential and wisdom. The learning attitude of each student was serious, which enabled us to keep up with technology and assimilate into the lives of modern people. This caused us to be highly interested in learning. I hope that this course can continue to be offered, so that more people can learn new technology and keep up with technology and young people. (S10, 2017/05/26; P1; 24-26)

The instructors were kind and careful, which is very rare. (S4; 2017/05/26; P1; 12)

(B)IT Literacy Among Older Adults

In the four IT literacy dimensions, "IT and human society" was rated the best and "information use and problem solving" was the weakest. The posttest mean values of each indicator were higher than the pretest values. The pretest and posttest mean values of overall IT literacy were 3.03 and 4.19, respectively. A t-test with a significance level of $\mathrm{p}=.001$ indicated that IT literacy of the participants increased significantly after the courses. The mean values of the four dimensions of the scale also increased significantly $(\mathrm{p}=.001$; Table 2 and 3$)$. The third dimension, "information use and problem-solving," increased the most following the course.

Table 2.Mean (SD) of the IT Literacy Questionnaire for Older Adults

\begin{tabular}{llll}
\hline \multicolumn{1}{c}{ Dimension } & \multicolumn{2}{c}{ Man (SD) } & Differences \\
\cline { 2 - 3 } & \multicolumn{1}{c}{ Pretest } & \multicolumn{1}{c}{ Posttest } & \\
\hline I. Information needs and access & $\begin{array}{l}3.1019 \\
(1.26668)\end{array}$ & $4.3703(.66121)$ & 1.26833 \\
\hline II. Information evaluation & $\begin{array}{l}3.1575 \\
(1.05798)\end{array}$ & $4.0278(.82584)$ & .87028 \\
\hline III. Information use and & $\begin{array}{l}2.3422 \\
(1.12842)\end{array}$ & $3.8800(.92245)$ & 1.53778 \\
problem solving & $\begin{array}{l}3.4994 \\
(1.01897)\end{array}$ & $4.4822(.53166)$ & .98278 \\
\hline IV. IT and human society & $\begin{array}{l}\text { 3.0255 } \\
(1.02059)\end{array}$ & $4.1898(.62729)$ & 1.16435 \\
\hline Average of overall indicators & & \\
\hline
\end{tabular}

Table 3.Statistical Analysis of the IT Literacy Questionnaire for Older Adults

\begin{tabular}{lccccc}
\hline \multicolumn{1}{c}{ Dimension } & \multicolumn{3}{c}{ Paired differences } & t & \multirow{2}{*}{$\begin{array}{c}\text { Sig. } \\
\text { (2-tailed) }\end{array}$} \\
\cline { 2 - 4 } & Mean & SD & $\begin{array}{c}\text { Std. } \\
\text { Error }\end{array}$ & & \\
\hline $\begin{array}{l}\text { I. Information needs } \\
\text { and access }\end{array}$ & 1.26833 & 1.15142 & .19190 & 6.609 & $.000^{* * *}$ \\
\hline $\begin{array}{l}\text { II. Information } \\
\text { evaluation }\end{array}$ & .87028 & 1.25775 & .20963 & 4.152 & $.000^{* * *}$ \\
\hline $\begin{array}{l}\text { III. Information use and } \\
\text { problem solving }\end{array}$ & 1.53778 & .98022 & .16337 & 9.413 & $.000^{* * *}$ \\
\hline $\begin{array}{l}\text { IV. IT and human } \\
\text { society }\end{array}$ & .98278 & .93952 & .15659 & 6.276 & $.000^{* * *}$ \\
\hline $\begin{array}{l}\text { Average of overall } \\
\text { indicators }\end{array}$ & 1.16435 & .95628 & .15938 & 7.305 & $.000 * * *$ \\
\hline$* p<.05, * * p<.01, * * * p<.001$ & & & & \\
\hline
\end{tabular}

\section{(C)Future Learning Willingness}

Regardless of the pretest or posttest, the participants were eager to participate in courses on using smart devices to enhance information literacy and make life more convenient. They were highly willing to continue learning. After participating in the course, the willingness of the participants to use smart devices to study online on their own was significantly enhanced.

\begin{tabular}{|c|c|c|c|}
\hline & & Mean & $\mathrm{SD}$ \\
\hline \multirow{2}{*}{$\begin{array}{l}\text { 1. I may learn autonomously on the Internet using } \\
\text { smart devices. }\end{array}$} & Pretest & 2.89 & 1.214 \\
\hline & Posttest & 4.17 & .845 \\
\hline \multirow{2}{*}{$\begin{array}{l}\text { 2. I think that continuing to learn how to use smart } \\
\text { devices is helpful for increasing my IT ability. }\end{array}$} & Pretest & 4.22 & .832 \\
\hline & Posttest & 4.61 & .494 \\
\hline \multirow{2}{*}{$\begin{array}{l}\text { 3. I am willing to continue learning IT to make my } \\
\text { life easier. }\end{array}$} & Pretest & 4.50 & .561 \\
\hline & Posttest & 4.75 & .439 \\
\hline
\end{tabular}

From the data above, it was discovered that "Brave across the 
Taiwan Strait" had immediate effect on the learning outcomes of indigenous fifth and sixth grade students in terms of mastering Taiwanese history.

\section{Conclusion and suggestion}

\section{A. Conclusion}

According to the above, the following can be concluded:

1. Learning how to use smart devices helps enhance the basic IT literacy necessary for daily life. The baseline IT literacy of the participants was moderate, but it was significantly improved by as much as 1 point after completing the course. Moreover, the participants were willing to continue their studies.

2. Repeated reminders and review help improve older adults' learning. A slower teaching pace is more suited to teaching older adults because they often have shorter memories than younger students. In particular, using handouts can help ease older adults' fear of learning. The speed of teaching can be adjusted depending on the class progress, and teachers must review previous topics at the start of each lesson before progressing to something new. The teaching objectives can be cut into smaller tasks, allowing for gradual but continuous progress that provides older adults with a sense of accomplishment in their learning.

3. Teaching assistant teams and small-group instruction improve teaching and learning efficiency. Older adults require patient guidance to help reduce their fear of using IT. Teaching assistants can help teachers with guiding students. This helps older adults learn effectively because they are more likely to receive individual attention, allowing the teaching process to proceed smoothly.

4. Familiarity with the class location, peer support, and a relaxed learning atmosphere help older adults learn more effectively.

B. Suggestion

1. The demographic survey of the participants in the present study revealed that the average older adult using smart devices in Taiwan is likely to use the instant messaging app LINE; however, the majority of participants were still unfamiliar with the basic settings and functionality of their smart devices. Consequently, they were unwilling to make adjustments to their devices. Once students understand the basic functionality of smart devices, follow-up topics on a variety of apps can be conducted smoothly. Many older adults struggle to use common IT tools to solve daily life problems. Thus, the design of any curriculum teaches how to use smart devices should be linked to real-life situations. This helps to enhance interest in learning among older adults, meaning they are more willing to use their smart devices to solve and enhance their personal IT literacy.

2. Prior to starting a course to teach older adults about smart devices, information regarding the students' experience with such devices and IT literacy should be gathered. Grouping students according their experience and IT literacy means that learning groups can have a mix of student abilities. This allows the stronger students to help the weaker students. In addition, teaching assistants should be employed to improve teaching effectiveness.

3. To reduce frustration in the learning process, we recommend relevant learning aids. Because older adults often have poor vision or inflexible fingers, styluses can be provided to help students tap on their smart device screens.

4. We can encourage those participants with better ability to share as teaching seeds in local area to encourage more elder adults willing to understand the application of smart devices and expand learning benefits through peer power.

\section{Acknowledgment}

This research is part of the project "Effects on information literacy and learning experience of senior citizens through the courses of information technology application" of the R.O.C. Taiwan Ministry of Science.

\section{References}

[1] Institute for Information Industry. "New aging life circle."Acces sed on: May. 12, 2017. [Online]. Available:https://in.ideas.iii.org. tw/index.php/ingroup/2015-10-19-01-44-31

[2] J. Y.Chao, "Effects on information literacy and learning experience of senior citizens through the courses of information technology application. Research project midterm report" ( 105-2511-S-152 -002 -MY2) .Ministry of Science and Technology,Taiwan, 2017.

[3] Taiwan Network Information Center. "Survey report of Taiwan b roadband network usage in 2016."Accessed on: Mar. 21, 2017. [Online].Available:https://www.twnic.net.tw/download/200307/ 200307index.shtml

[4] Taiwan Network Information Center. "Survey report of Taiwan b roadband network usage in 2017." Accessed on: Feb. 1, 2018. [O nline]. Available:https://www.twnic.net.tw/download/200307/20 0307 index.shtml

[5] H. Y. McClusky, Education: Background and issues. Washington, DC: White House Conference on Aging, 1971.

[6] Y. H.Lee,\&C. T.Yeh. "The process of older adults' motivations of continuing participation and learning,"Journal of Humanities and Social Sciences, Vol. 10, pp.51-63,2014.

[7] F. S. Huang, \&G. D. Yang, Gerontology. Taipei: Wu-Nan, 2011.

[8] H. C. Wei, Active aging learning in Taiwan. Taipei: Wu-Nan, 2012.

[9] C.McClure, "Network literacy: a role for libraries?" Information Technology and Libraries. Vol. 13, pp.115-125, 1994.

[10] C.Yu, \&C.H.Huang, "Motivating and Obstacles Factors for Elderly Using InternetService,"Electronic Commerce Studies, Vol. 11, pp.195-228, 2013.

[11] M. F.Chen, "Information literacy and the use of social media for senior learners,"M.S. thesis, Dept. Information and Communication, Southern Taiwan University of Science and Technology, Tainan, Taiwan, 2016.

[12] J. Y.Chao, "Effects on information literacy and learning experience of senior citizens through the courses of information technology application. Research project midterm report" ( 105-2511-S-152 -002 -MY2 ) .Ministry of Science and Technology,Taiwan, 2017.

[13] G. R.Morrison, S. M.Ross, and J. E.Kemp,Designing effective instruction (6th ed.). New York: John Wiley \& Sons Inc, 2009.

[14] Y. H.Chen, "Action research of carrying out using tablet PC courses for middle-aged and elder adults,"M.S. thesis, Dept. elder education, National Chung Cheng Univ., Chiayi. Taiwan, 2014.

[15] H. C.Wei, \&M. H. Liang, "The development of an assessment sc ale of teaching strategies for elder education," Hungkuan Acade mic Review, Vol. 80, pp.39-56, 2017.

[16] A.Collins, J. S.Brown, \&S. E.Newman, "Cognitive apprenticeshi p: teaching the craft of reading, writing, and mathematics," In L. B. Resnick (Ed.), Knowing, learning, and instruction: Essays in honor of Robert Glaser (pp.453-494). Hillsdale, NJ: Erlbaum, 19 89.

[17] S. F. Jiang, "Intergenerational Learning in the Low Fertility Rate and Population Ageing Society the Feasible Practice of Younge r Generation as the Elderly's E-Tutor,"Journal of Education Res earch, Vol. 281, pp.81-98, 2017. doi:10.3966/168063602017090 281007 